\title{
Variation of monolayer behaviour and molecular packing in zinc arachidate LB films with subphase $\mathrm{pH}$
}

\author{
A. Dhanabalan ${ }^{\mathrm{a}, *}$, N. Prasanth Kumar ${ }^{\mathrm{b}}$, S. Major ${ }^{\mathrm{b}}$, S.S. Talwar ${ }^{\mathrm{a}}$ \\ ${ }^{a}$ Department of Chemistry, Indian Institute of Technology, Bombay 400 076, India \\ ${ }^{\mathrm{b}}$ Department of Physics, Indian Institute of Technology, Bombay 400 076, India
}

\begin{abstract}
Monolayer characteristics and multilayer LB films of zinc arachidate $(\mathrm{ZnA})$ have been studied as a function of subphase $\mathrm{pH}$ in the range 4.9-8.0. The monolayer stability was found to be strongly dependent on the subphase $\mathrm{pH}$. Measurement of bilayer spacings in transferred multilayers using X-ray diffraction revealed that depending on subphase $\mathrm{pH}$, three types of molecular packing arrangements corresponding to alkyl chain tilt angles of $0^{\circ}, 19^{\circ}$ and $31^{\circ}$ are possible in $\mathrm{ZnA}$ multilayers. In certain ranges of subphase $\mathrm{pH}$, more than one type of packing arrangements were found to coexist. These results suggest that the packing arrangement in ZnA multilayers is significantly affected by the properties of the monolayer at the air-water interface and may not be simply related to metal ion electronegativity.
\end{abstract}

Keywords: Zinc arachidate; Subphase pH; Monolayer; Langmuir-Blodgett film; Molecular packing

\section{Introduction}

The Langmuir-Blodgett (LB) technique is currently employed to fabricate organized molecular layered structures of a variety of functionalized molecules [1,2]. Longchain fatty acids and their divalent salts have been extensively studied model LB systems both as Langmuir monolayers as well as LB multilayers [3]. Recent atomic force microscopy (AFM) studies on a series of divalent fatty acid salts, namely $\mathrm{Pb}, \mathrm{Cd}, \mathrm{Mg}, \mathrm{Mn}, \mathrm{Ca}, \mathrm{Ba}$ and $\mathrm{Zn}$ arachidates/ stearates have been used to infer that as the electronegativity of the metal ion decreases, the bonding between the metal ion and the fatty acid carboxylate ion tends to acquire stronger ionic character, which has been associated with a larger headgroup area required per molecule as compared to covalently bonded metal ions [4,5]. This, in turn, induces alkyl chains to tilt to keep the van der Waal's chain-chain interaction intact in the plane perpendicular to the chains. Cadmium arachidate multilayers are known $[5,6]$ to pack in an ideal centred rectangular (herringbone) lattice [7], with chains normal to the layer. This has been attributed to the relatively higher electronegativity of cadmium (1.7) [5]. Most of the other arachidates in the above series also follow the above trend with the exception of zinc arachidate [5]. Zinc arachidate (ZnA) multilayers are reported [8] to pack in a distorted hexagonal lattice with the chains tilted at an angle of $\sim 30^{\circ}$ towards the nearest neighbour. This contrast in packing behaviour between zinc and cadmium arachidates is interesting because the electronegativity of zinc (1.6) is quite close to that of cadmium. It thus appears that the molecular packing in divalent salts may not be simply related to the electronegativity of the metal ion or even the ionic radius and possibly necessitates a deeper understanding of the relationship between the properties of the monolayer on the water surface and the structure of the transferred multilayers. The composition, structure and stability of the monolayer is known to be sensitive to the type and concentration of the metal ion and the $\mathrm{pH}$ of the subphase which controls the extent of metal ion complexation with the acid head group [9].

In this work we have undertaken a study of ZnA LB films in view of their interesting molecular packing behaviour. We report here on the monolayer characterization, composition and structure of $\mathrm{ZnA}$ multilayers studied as a function of different subphase conditions characterized by its $\mathrm{pH}$. 


\section{Experimental}

Arachidic acid (Aldrich, 99\%) was used as received. Chloroform (HPLC grade) was used as spreading solvent $(1 \mathrm{mg} / \mathrm{ml}, 100 \mu \mathrm{l})$. Deionized and ultrafiltered water (Millipore) was used as subphase. A $10^{-5} \mathrm{M}$ solution of anhydrous $\mathrm{ZnCl}_{2}$ was added to the subphase and $\mathrm{pH}$ was adjusted to desired values by adding dilute solution of $\mathrm{HCl}, \mathrm{NaOH}$ and $\mathrm{NaHCO}_{3}$. Surface pressure-mean molecular area isotherm studies and multilayer LB depositions were carried out at $21.5^{\circ} \mathrm{C}$ using a KSV-3000 instrument kept in a clean room. Quartz and $\mathrm{CaF}_{2}$ were used as substrates and were cleaned by employing standard procedures. The monolayer was compressed with a constant barrier speed of $3 \mathrm{~mm} / \mathrm{min}$ and all the multilayer depositions were carried out at a surface pressure of $31 \mathrm{mN} / \mathrm{m}$. The compressed monolayer was transferred by vertical dipping method at a speed of $3 \mathrm{~mm} /$ min. Typically, 25 layers were transferred in each case. Xray diffraction (XRD) and Fourier transform infrared (FTIR) studies were carried out with Philips PW1820 powder diffractometer ( $\mathrm{Cu}$ target) and Nicolet (Impact-400) instruments, respectively.

\section{Results and discussion}

In order to study the effect of subphase $\mathrm{pH}$ on the nature of the isotherm, all the other parameters like subphase temperature, compression speed, spreading solution, concentration and monolayer aging time were kept unchanged. The subphase $\mathrm{pH}$ was varied between 4.9 and 8.0. Condensed monolayers were observed at all the subphase $\mathrm{pH}$ values and some typical isotherms are shown in Fig. 1. At a pH value of 4.9 , the isotherm exhibited a well-defined liquid condensed region, indicating the presence of a mixture of acid and salt [3]. The limiting mean molecular area obtained by extrapolating the solid region of the $\pi-A$ isotherm curve is close to $\sim 20 \AA^{2}$, which matches well with the reported value for unionized fatty acid monolayer [3]. Similar isotherms were observed up to the subphase $\mathrm{pH}$ of 6.4. At subphase $\mathrm{pH}$ above 6.4, the liquid condensed region completely disappeared and a steep rise in surface pressure was noticed. A typical isotherm for subphase $\mathrm{pH}$ of 6.6 is shown in Fig. 1. This isotherm behaviour indicates that the monolayer con-

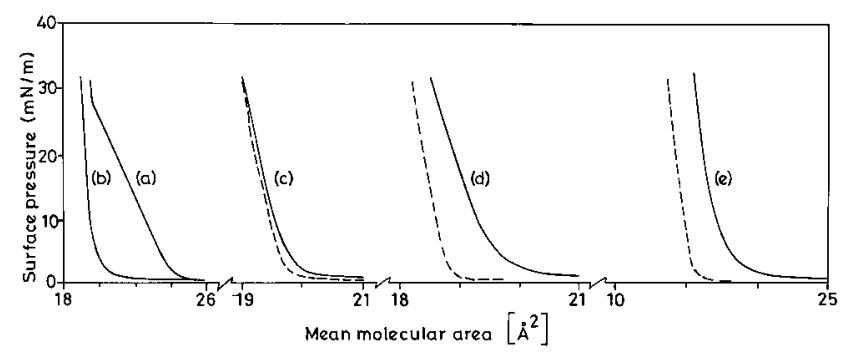

Fig. 1. $\pi-A$ isotherms of $\mathrm{ZnA}$ monolayers at subphase $\mathrm{pH}$ values of (a) 4.9, (b) 6.6, (c) 7.43, (d) 7.82 and (e) 8.0. The dashed curves represent second compression.

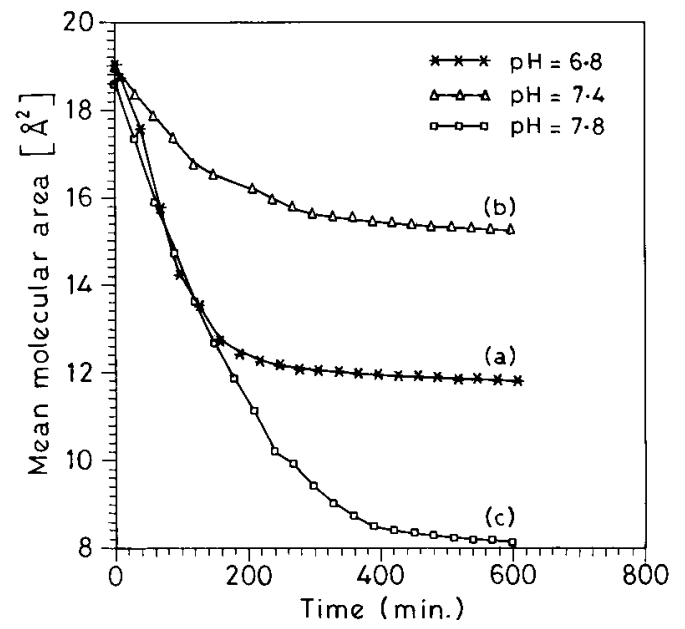

Fig. 2. Variation of mean molecular area $(\mathrm{mmA})$ as a function of time (with surface pressure held at $31 \mathrm{mN} / \mathrm{m}$ ) at subphase $\mathrm{pH}$ values of (a) 6.8 , (b) 7.4 and (c) 7.8 .

sists essentially of arachidate salt [10]. It may be noted that though all the isotherms above the subphase $\mathrm{pH}$ of $\sim 6.4$ were similar in nature, the stability of the monolayer was found to be dependent on subphase $\mathrm{pH}$ as described below.

Up to a subphase $\mathrm{pH} \sim 7.2$, the first and second compression isotherms were identical and practically no hysteresis was observed even during subsequent isotherms. However, above the subphase $\mathrm{pH}$ of 7.2, the isotherms exhibited hysteresis and a decrease in limiting mean molecular area on successive compressions was observed. Typical first and second compression isotherms for subphase $\mathrm{pH}$ values of $7.43,7.82$ and 8.0 are shown in Fig. 1. Up to a subphase $\mathrm{pH}$ $\sim 7.8$, the changes in limiting mean molecular area observed in the second compression were relatively small and the magnitude of the change was found to decrease on successive compressions. In comparison, at higher subphase $\mathrm{pH}$, the limiting mean molecular area changes in successive compression cycles was much larger.

In order to further examine monolayer stability, the monolayer was held in a compressed state at a surface pressure of $31 \mathrm{mN} / \mathrm{m}$ for a period of $10 \mathrm{~h}$. The change in mean molecular area $(\mathrm{mmA})$ was monitored as a function of time, for several subphase $\mathrm{pH}$ values in the range of 6.5-8.0 and typical results are shown in Fig. 2. At all the subphase $\mathrm{pH}$ values in the above range, the monolayer behaviour was qualitatively similar as the $\mathrm{mmA}$ initially decreased and later saturated at a significantly lower value. However, based on the saturation values of $\mathrm{mmA}$, three subphase $\mathrm{pH}$ ranges could be qualitatively identified. In the subphase pH range of $6.5-7.2$, the mmA saturated $\sim 10-12 \AA^{2}$, while in $\mathrm{pH}$ range of 7.2-7.5 the saturation value of $\mathrm{mmA}$ was $\sim 15-16 \AA^{2}$. In comparison, above the subphase $\mathrm{pH}$ of 7.5 , the $\mathrm{mmA}$ was found to saturate at much lower values $\sim 5-8$ $\AA^{2}$. The variation of mmA with time for the three $\mathrm{pH}$ values of 6.8, 7.4 and 7.8 shown in Fig. 2 typically represent the monolayer stability behaviour in the above three ranges of subphase $\mathrm{pH}$. It may also be noted that in the prolonged 
compressed state, no crystalline particles were visually seen on the subphase at any of the above $\mathrm{pH}$ values. Further, at all subphase $\mathrm{pH}$ values, the monolayer was found to collapse around a surface pressure of $50 \mathrm{mN} / \mathrm{m}$.

The poor stability of the monolayer is normally associated with either dissolution of material into the subphase (as micelles or reverse micelles) or the formation of multilayer stacks on the surface of water. In the present case, changes in monolayer composition affecting its stability may also not be ruled out. It is known that above a certain subphase $\mathrm{pH}$, the metal ion undergoes hydrolysis to form metal hydroxides [11]. The incorporation of hydroxylated zinc salts at higher subphase $\mathrm{pH}$ values has been suggested earlier [12]. The possibility of metal ion hydrolysis is indicated by the observation that in the high $\mathrm{pH}$ subphase solutions (above 7.5), a turbid material was noticed to settle down after an aging time of an hour or so (in such cases, the subphase solution was filtered prior to use in the LB experiments).

$\mathrm{ZnA}$ multilayers were deposited at different subphase $\mathrm{pH}$ values by transferring the monolayers either immediately after the first compression or after the saturation of $\mathrm{mmA}$ was complete ( $\approx 10 \mathrm{~h}$ of compressed state). In the case of films transferred immediately after the first compression, the transfer ratio was nearly unity irrespective of the subphase $\mathrm{pH}$. In contrast, in the case of films transferred after the saturation of $\mathrm{mmA}$, the transfer ratio was nearly unity below the subphase $\mathrm{pH}$ of 7.5 , while at higher subphase $\mathrm{pH}$, very poor transfer ratio $(\leq 0.5)$ were observed. It may be mentioned that in none of the above cases could any crystalline particles be seen during the transfer process.

At each value of the subphase $\mathrm{pH}$, the films deposited under the two above conditions revealed qualitatively similar characteristics when analysed by FTIR and powder XRD techniques, as described below. It may, however, be mentioned that in the case of multilayers transferred immediately after the first compression, sharp and intense XRD peaks up to $\sim 10$ orders were seen. In contrast, the multilayers transferred after the saturation of $\mathrm{mmA}$ exhibited broad and weak peaks up to only 3-4 orders, which indicated that these films possess a poorly ordered layered structure. In what follows, therefore, we present the results of FTIR and XRD studies of films which were transferred immediately after the first compression.

Typical FTIR spectra of the films on calcium fluoride substrate are shown in Fig. 3. The film deposited at a subphase $\mathrm{pH}$ of 4.9 exhibited strong characteristic absorptions at 1700 and $1548 \mathrm{~cm}^{-1}$, corresponding to carbonyl stretching vibrations of un-ionized and ionized acid groups, respectively. This result corroborates well with the isotherm studies that at subphase $\mathrm{pH}$ of 4.9 , the monolayer contains a mixture of both acid and salt. Films deposited at a subphase $\mathrm{pH}$ of 7.3 exhibited a strong absorption peak at $1548 \mathrm{~cm}^{-1}$ and no peak at $1700 \mathrm{~cm}^{-1}$, indicating that the film contained only arachidate salt. This was typical of the films deposited in the subphase $\mathrm{pH}$ range of $6.6-7.3$. The films deposited at

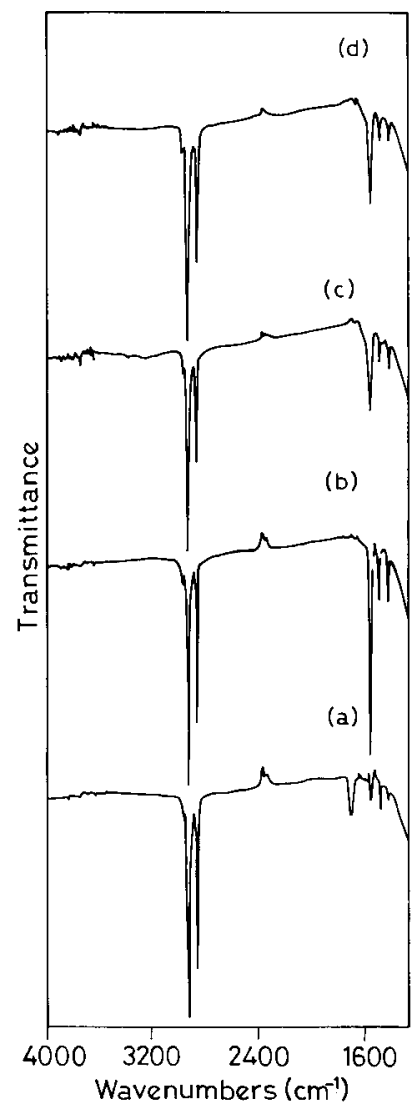

Fig. 3. FTIR spectra of ZnA multilayers deposited at subphase $\mathrm{pH}$ values of (a) 4.92 , (b) 7.3 , (c) 7.4 and (d) 7.8 .

the subphase $\mathrm{pH}$ values of 7.4 and 7.8 showed similar spectra, indicating that all these films also contained mainly arachidate salt. However, in these films, a weak and broad absorption in the hydroxyl region was observed which may have arisen due to the presence of partially hydrolysed zinc salts. It is thus possible that the films deposited in the subphase $\mathrm{pH}$ range of 7.4-7.8 may have some hydroxide content.

The X-ray diffraction studies of ZnA multilayers deposited at different subphase $\mathrm{pH}$, however, revealed a strong dependence of the layered structure and molecular packing on the subphase $\mathrm{pH}$. The results are shown in Fig. 4. The film deposited at subphase $\mathrm{pH} \sim 4.9$ exhibited only weak and broad diffraction peaks, possibly due to the presence of mixture of acid and salt. The bilayer distance calculated from the XRD pattern was $47 \pm 0.5 \AA$. All the films deposited below a subphase $\mathrm{pH}$ of 6.4 exhibited similar XRD spectra. In contrast, the film deposited at a subphase $\mathrm{pH}$ of 6.6 exhibited a set of sharp and intense diffraction peaks with a bilayer spacing of $\sim 47 \AA$. The bilayer spacing of $\sim 47$ $\AA$ corresponds to a chain axis tilt angle of $\sim 31^{\circ}$, assuming the height of the zinc arachidate molecule to be $27.5 \AA$ [1]. The film deposited at a subphase $\mathrm{pH}$ of 7.18 exhibited a similar XRD pattern except for a shoulder in the thirdorder peak. The XRD pattern for the film deposited on a subphase $\mathrm{pH}$ of 7.43 shows that in addition to the intense set 


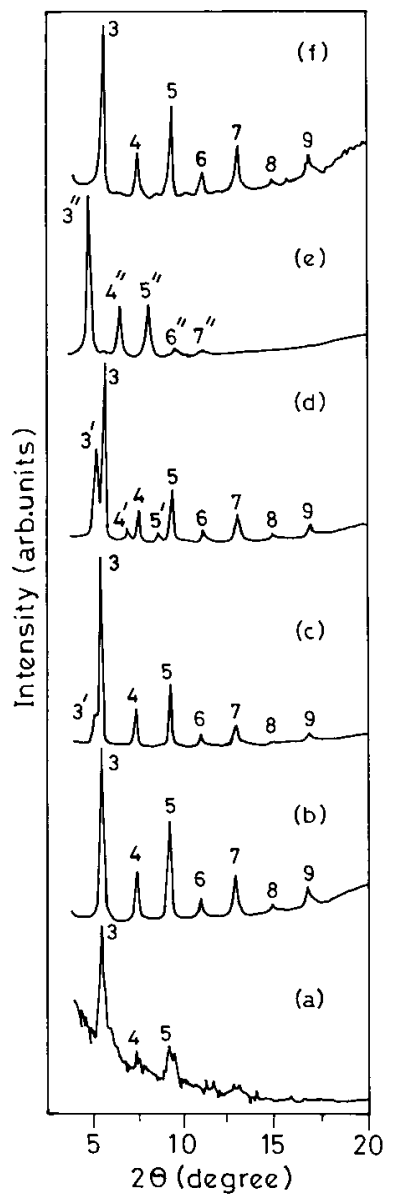

Fig. 4. XRD patterns for $\mathrm{ZnA}$ multilayers deposited at subphase $\mathrm{pH}$ values of (a) 4.9, (b) 6.6, (c) 7.18, (d) 7.43, (e) 7.52 and (f) 7.8.

of peaks corresponding to the bilayer spacing of $47 \AA$ $(3,4,5 \ldots)$, there exists an additional set of peaks $\left(3^{\prime}, 4^{\prime}\right.$, $\left.5^{\prime} \ldots\right)$, corresponding to a bilayer spacing of $\sim 52 \pm 0.5 \AA$. The presence of two sets of diffraction peaks is attributed to the coexistence of two types of packing arrangements in the multilayer. It may be noted that the bilayer spacing of $\sim 52 \AA$ corresponds to a molecular tilt of $\sim 19^{\circ}$. As the subphase $\mathrm{pH}$ was increased further, the pattern (not shown) corresponding to the bilayer spacing of $\sim 52 \AA$ tended to become prominent. However, the film deposited at a subphase $\mathrm{pH}$ of 7.52 exhibited an entirely new set of diffraction peaks ( $3^{\prime \prime}$, $4^{\prime \prime}, 5^{\prime \prime} \ldots$.) corresponding to a bilayer spacing of $\sim 55 \AA$, implying that the molecules were packed normal to the substrate in this case. Strikingly, as the $\mathrm{pH}$ was increased to 7.8, the corresponding film exhibited a diffraction pattern corresponding to a bilayer spacing of $\sim 47 \AA$. Thus barring the $\mathrm{pH}$ range of 7.3-7.5 the bilayer spacing in zinc arachidate multilayers remains $\sim 47 \AA$, which is consistent with the earlier observation made on this system [8]. It may also be mentioned that the above results were extremely reproducible except for minor variation in the range of $\mathrm{pH}$ values $( \pm 0.2)$ in which the structural transitions in the deposited film were observed. Furthermore, the films exhibiting various types of structures as described above were found to be stable and the XRD patterns remained unchanged over several months.

The above results suggest that three types of molecular packing arrangements are possible in $\mathrm{ZnA}$ multilayers. The transitions between these packing arrangements take place at reasonably well defined narrow ranges of $\mathrm{pH}$ values. Furthermore, in certain ranges of $\mathrm{pH}$ values, two and occasionally all three types of packing arrangements were found to coexist. The coexistence of three homologous forms consisting of stacks of molecular tilts of $\sim 21^{\circ}, 28^{\circ}$ and $36^{\circ}$ have been reported earlier [13] in the case of arachidic acid and some other fatty acid LB films. The three types of packing arrangements in the present case of zinc arachidate correspond to alkyl chain tilt angles of $0^{\circ}, 19^{\circ}$ and $31^{\circ}$ with respect to the layer normal. It may be noted that the ideal close packing arrangements worked out for long-chain fatty acids by Kitaigorodskii [7] include three arrangements under the orthorhombic $\{\mathrm{R}\}$ subcell with chain tilt angles of $0^{\circ}, 19^{\circ}$ and $31.5^{\circ}$, which, using the nomenclature of Peterson and Russel [14], may be identified as $R(001)$, $\mathrm{R}(011)$ and $\mathrm{R}(111)$ packing, respectively. Most interestingly, our results show that with increase in subphase $\mathrm{pH}$ above 7.2, the chain tilt angle decreases and becomes zero. However, on further increase of subphase $\mathrm{pH}$ to 7.8 , the usually observed packing arrangement with a tilt angle of $\sim 30^{\circ}$ was restored. These observations underline the sensitivity of the molecular packing arrangement to the subphase conditions. It is, however, important to note that though the monolayers transferred in the present case were not stable, in the strict sense of the term, the multilayers exhibited reproducible layered structures at all subphase $\mathrm{pH}$ values. Furthermore, it appears that both at low and high $\mathrm{pH}$ ranges, the $\mathrm{mmA}$ has a tendency to decrease to rather low values $\left(\leq 10 \AA^{2}\right)$ and the transferred multilayers exhibit large alkyl chain tilt angles $\sim 30^{\circ}$. In contrast, in the intermediate $\mathrm{pH}$ range (7.2-7.5), the monolayer stabilizes at relatively larger mmA values $\left(\sim 15-16 \AA^{2}\right)$ and the transferred multilayers consist of alkyl chains normal to the substrate. The origin of the dependence of monolayer behaviour and multilayer packing arrangements on the subphase $\mathrm{pH}$ probably lie in the monolayer composition changes resulting from complex zinc ion hydrolysis equilibria [11].

\section{Conclusions}

The monolayer stability behaviour and molecular packing arrangement in $\mathrm{ZnA}$ multilayers are significantly affected by subphase $\mathrm{pH}$. Alkyl chain tilt angles lower than that usually reported $\left(\sim 30^{\circ}\right)$ for $\mathrm{ZnA}$ multilayers have been observed for the first time. These results point out the limited nature of the correlation between metal ion electronegativity and the molecular packing arrangement in the multilayers of divalent fatty acid salts, and imply that the complex nature of the relationship between the properties of the monolayer on water surface and the structure of trans- 
ferred multilayers needs to be explored. There is probably a need to search for such behaviour patterns in the easily hydrolysable divalent ion fatty acid salts.

\section{Acknowledgements}

The financial support for the work was provided by the Department of Science and Technology and the Board of Research in Nuclear Sciences, Department of Atomic Energy, Government of India.

\section{References}

[1] A. Ulman, An Introduction to Ultrathin Organic Films: From Langmuir-Blodgett to Self-Assembly, Academic Press, London, 1991.

[2] G. Roberts (ed.) Langmuir-Blodgett Films, Plenum Press, New York, 1990
[3] G.L. Gaines, Insoluble Monolayers at Liquid-Gas Interface, Interscience, New York, 1966.

[4] D.K. Schwartz, R. Viswanathan, J. Garnaes, J.A. Zasadzinski, J. Am. Chem. Soc. 115 (1993) 7374.

[5] J.A. Zasadzinski, R. Viswanathan, L. Madsen, J. Garnaes, D.K. Schwartz, Science 263 (1994) 1726.

[6] P. Tippmann-Krayer, R.M. Kenn, H. Möhwald, Thin Solid Films 210-211 (1992) 577.

[7] A.I. Kitaigorodskii, Organic Chemical Crystallography, Consultant Bureau, New York, 1961.

[8] R. Viswanathan, L. Madsen, J.A. Zasadzinski, D.K. Schwartz, Science 269 (1995) 51.

[9] B.P. Binks, Adv. Colloid Interface Sci. 34 (1991) 343.

[10] D.J.M. Linden, J.P.K. Peltonen, J.B. Rosenholm, Langmuir 10 (1994) 1592.

[11] C.F. Baes Jr., R.E. Mesmer, The Hydrolysis of Cations, Wiley-Interscience, New York, 1976.

[12] D.M. Taylor, J.N. Lambi, Thin Solid Films 243 (1994) 384.

[13] A. Leuthe, L.F. Chi, H. Riegler, Thin Solid Films 243 (1994) 351.

[14] I.R. Peterson, G.J. Russel, Phil. Magazine A 49 (1984) 463. 